\title{
Influence of Achlorhydria on Aspirin-induced Occult Gastrointestinal Blood Loss : Studies in Addisonian Pernicious Anaemia
}

\author{
D. J. B. ST. JOHN,* M.B., M.R.A.C.P., M.R.C.P. ; F. T. MCDERMOTT, $†$ M.B., F.R.C.S., F.R.A.C.S.
}

\begin{abstract}
ummary: The effect of aspirin (acetylsalicylic acid) ingestion on occult gastrointestinal blood loss has been studied in patients with treated Addisonian pernicious anaemia and proved achlorhydria and in control patients able to secrete hydrochloric acid. A highly significant increase in gastrointestinal blood loss (1.9 $\mathrm{ml}$./day of treatment) occurred with aspirin ingestion in the achlorhydric patients. The control group had a significantly greater increase in blood loss $(4.29 \mathrm{ml}$./ day of treatment). Thus aspirin can produce occult gastrointestinal blood loss by a mechanism unrelated to hydrochloric acid. Half of the control patients had losses of similar magnitude to those in the pernicious anaemia group, and the degree of blood loss in individual control patients appeared unrelated to gastric acidity. Differences in gastric mucosal characteristics, in the rate of gastric emptying, or in systemic effects of aspirin may explain the variation between individuals in the degree of occult gastrointestinal blood loss after aspirin.
\end{abstract}

\section{Introduction}

The relationship of gastric acidity to the increase in occult gastrointestinal blood loss found in most subjects after aspirin ingestion (Pierson, Holt, Watson, and Keating, 1961) remains controversial (Davenport, 1965; Menguy, 1966; Overholt and Pollard, 1968). Though the presence of hydrochloric acid appears important or even essential for aspirin-induced bleeding in experimental animals (Davenport, 1965; Davison, Hertig, and DeVine, 1966; Brodie and Chase, 1969) there is some evidence to the contrary in man (Winkelman and Summerskill, 1961; Croft and Wood, 1967). This evidence, however, is not sufficient to allow the definite conclusion that aspirin can cause bleeding in the absence of hydrochloric acid. We have therefore studied patients with Addisonian pernicious anaemia and proved achlorhydria and the results obtained have been compared with those of a group of patients able to secrete hydrochloric acid.

\section{Methods}

Measurement of Gastrointestinal Blood Loss.-Gastrointestinal blood loss was measured by the radioactive chromium technique (Roche, Perez-Gimenez, Layrisse, and Di Prisco, 1957). Nine millilitres of venous blood was labelled in vitro with $100 \mu \mathrm{Ci}$ of ${ }^{51} \mathrm{Cr}$-sodium chromate (Mollison, 1961). The radioactivity of homogenized faecal specimens was measured in a large volume counter between twin cylindrical plastic scintillators $(18 \mathrm{~cm}$. diameter by $10 \mathrm{~cm}$.) coupled to 18 $\mathrm{cm}$. diameter photomultiplier tubes. Outputs were summed and fed into a Nuclear Enterprises Edinburgh Scaler. A source to background counting ratio of 40 was obtained from a sample of $1 \mu \mathrm{Ci}$ of ${ }^{51} \mathrm{Cr}$-sodium chromate.

Haematological Methods.-Serum vitamin $\mathrm{B}_{12}$ levels were assayed with the " $Z$ " strain of Euglena gracilis (normal laboratory range $170-700 \mathrm{pg} . / \mathrm{ml}$.). Serum folate levels were assayed with Lactobacillus casei ATCC 7469 (normal labora-

*Lecturer, Department of Medicine, Monash University, Alfred Hospital; Formerly Assistant Physician, Clinical Research Unit, Alfred Hospital, Melbourne, Australia.

+ Senior Lecturer, Department of Surgery, Monash University, Alfred Hospital, Melbourne, Australia. tory range 3-15 $\mathrm{ng} . / \mathrm{ml}$.) Vitamin $\mathbf{B}_{12}$ absorption was measured by the urinary excretion method (Schilling, 1953) with an oral dose of $0.5 \mu \mathrm{g}$. of vitamin $\mathrm{B}_{12}$ (activity $0.5 \mu \mathrm{Ci}$ of ${ }^{57} \mathrm{Co}$ ) and 48-hour urine collections (normal laboratory range 10$40 \%$ of administered dose). Lederle intrinsic factor was used to measure the response of the vitamin $B_{12}$ absorption to intrinsic factor.

\section{Patients Studied}

Fifteen patients with proved Addisonian pernicious anaemia and 15 control patients were selected for study. Their full consent was obtained after explanation of the nature and purpose of the investigation. The mean age of the patients with pernicious anaemia was 68 (range 40-89) years; there were nine women and six men. Macrocytosis and neutrophil hypersegmentation were present in the peripheral blood of all patients at the time of diagnosis. Bone marrow examination showed megaloblastic change in the 13 patients submitted to this investigation. Serum vitamin $B_{12}$ and serum folate levels ranged from 20 to $140 \mathrm{pg} . / \mathrm{ml}$. and from 3 to 32 ng./ml. respectively.

The immunofluorescent test for parietal cell antibodies was positive in 10 out of 14 patients. In all patients the diagnosis of pernicious anaemia was confirmed by a Schilling test, dose alone (range 0.3-6.5\%), and a Schilling test with intrinsic factor (range $11 \%-26 \%$ ). No patient received antibiotics in the interval between the Schilling test, dose alone, and the Schilling test with intrinsic factor. In all patients achlorhydria was confirmed by an augmented histamine test (Kay, 1953) after radiological positioning of the gastric tube. The patients were receiving regular injections of vitamin $B_{12}$ and peripheral blood examination was normal at the time of the present investigation. Gastric biopsies (Wood, Doig, Motteram, and Hughes, 1949) were performed on three patients and showed gastric atrophy in each instance.

The mean age of the 15 control patients was 64 (range 42-76) years; there were nine women and six men. In each patient gastric intubation was performed before a meal and the $\mathrm{pH}$ of the gastric contents was found to be below 2.5. Gastric acidity was measured both by a glass electrode $p H$ meter and by titration with $M / 10$ sodium hydroxide to the phenolphthalein end-point. In addition, a further test was done in seven patients to determine the maximal acid output. Gastric intubation was performed under radiological control, and pentagastrin (Peptavlon) was given by subcutaneous injection in a dose of $6 \mu \mathrm{g} . / \mathrm{kg}$. body weight. The maximal acid outputs ranged from 13 to $39 \mathrm{mEq}$./hour. The control patients had been receiving treatment for hypertension, diabetes mellitus, fractures, or ischaemic heart disease. Patients with gastrointestinal disease, with a history of anaemia, or on anticoagulant therapy were excluded from the group.

\section{Protocol}

Faecal collections were begun three days after labelling and were continued for 14 days. Plain aspirin was given in a dose of $2.4 \mathrm{~g}$./day for four days from the sixth day of faecal collection and it was taken four times daily, before meals, and at night. Faecal collections were continued for five days after 
cessation of aspirin ingestion to allow for delay in the appearance of blood, because of variations in gastrointestinal transit time. All patients abstained from alcohol during the period of investigation.

The total blood loss for the five days before drug ingestion was calculated and the mean basal blood loss per day was determined. The total blood loss for the subsequent nine days was calculated and the results were expressed as mean blood loss per day of treatment (Wood, Harvey-Smith, and Dixon, 1962). We have also expressed the results as the mean increase in blood loss per day of treatment with aspirin, a figure obtained by subtraction of the mean basal blood loss from the mean blood loss per day of treatment.

\section{Results}

The results are summarized in the Table and Fig. 1. Both achlorhydric and control groups lost increased amounts of blood after ingestion of aspirin. The differences in means between control and drug periods are highly significant in each instance. Both the mean basal blood loss and that after aspirin ingestion were significantly higher in the control group than in the patients with pernicious anaemia but, as Fig. 1 shows, half the patients without the disease did not increase their blood loss more than those with it. An illustration of the detailed results in one patient with pernicious anaemia, in whom gastric biopsy had revealed gastric atrophy, is shown in Fig. 2.

Gastrointestinal Blcod Loss in the Patients Studied

\begin{tabular}{|c|c|c|c|}
\hline & $\begin{array}{c}\text { Patients } \\
\text { With } \\
\text { Pernicious } \\
\text { Anaemia }\end{array}$ & $\begin{array}{l}\text { Control } \\
\text { Patients }\end{array}$ & $\begin{array}{c}\text { Significance } \\
\text { of Differences } \\
\text { Between } \\
\text { Groups } \\
\text { (Fisher-Beh- } \\
\text { rens Test) }\end{array}$ \\
\hline $\begin{array}{l}\text { Mean Basal Blood Loss (ml./day) } \pm \text { S.D. } \\
\text { Mean Blood Loss per Day of Treatment } \\
\text { with Aspirin (ml.) } \pm \text { S.D. } \\
\text { Mean Increase in Blood Loss per Day of } \\
\text { Treatment with Aspirin (ml.) } \pm \text { S.D. } \\
\text { Significance of Increase in Blood Loss } \\
\text { in Each Group (Student's } t \text { test). . . }\end{array}$ & $\begin{array}{l}0 \cdot 36 \pm 0 \cdot 17 \\
2 \cdot 26 \pm 1 \cdot 42 \\
1 \cdot 90 \pm 1 \cdot 30 \\
P<0 \cdot 001\end{array}$ & $\begin{array}{l}0.53 \pm 0 \cdot 26 \\
4 \cdot 82 \pm 2 \cdot 73 \\
4 \cdot 29 \pm 2 \cdot 60 \\
P<0.001\end{array}$ & $\begin{array}{l}\mathrm{P}<0.05 \\
\mathrm{P}<0.01 \\
\mathrm{P}<0.01\end{array}$ \\
\hline
\end{tabular}

The patient with pernicious anaemia who had a blood loss considerably greater than the other members of the group $(5.8 \mathrm{ml}$./day of treatment) had no atypical features apart from a negative test for parietal cell antibodies. The serum vitamin $B_{12}$ and serum folate levels were $25 \mathrm{pg} . / \mathrm{ml}$. and $25 \mathrm{ng} . / \mathrm{ml}$. respectively. Bone marrow examination showed megaloblastic changes. The Schilling test, dose alone, was $2.5 \%$ and the Schilling test with intrinsic factor was $26 \%$. Barium meal examination performed after measurement of blood loss with aspirin showed changes typical of gastric atrophy (Laws and Pitman, 1960). Exclusion of this patient's results did not affect the statistical significances shown in the Table.

No relationship was found in the control group between the increase in blood loss after aspirin and the acidity of the gastric aspirate. In the control patients with increases in blood loss above $3 \mathrm{ml}$./day of treatment the mean acid concentration was 66 (range 10-105) mEq./litre, and in the control patients with increases below $3 \mathrm{ml}$./day of treatment the mean acid concentration was 50 (range 3-100) mEq./litre. The maximal acid outputs obtained in four patients with increases in blood loss above $3 \mathrm{ml}$./day of treatment were $29.0,37 \cdot 2,38.0$, and $39.2 \mathrm{mEq}$./hour, respectively, and those in three patients with increases below that level were $13.0,20.0$, and $29.0 \mathrm{mEq}$./hour. The maximal acid output of $13 \mathrm{mEq}$./hour occurred in the patient with the lowest acid concentration in the single gastric aspirate (3.0 $\mathrm{mEq}$./litre). The increases in blood loss in all 30 patients studied were unrelated to age, sex, or blood group.

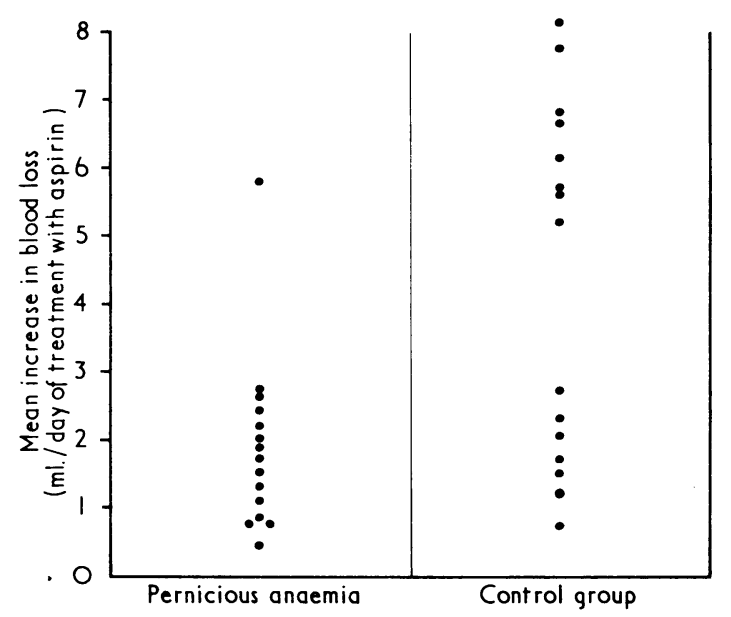

FIG. 1.-Comparison of increases in blood loss with aspirin in the two groups of patients.

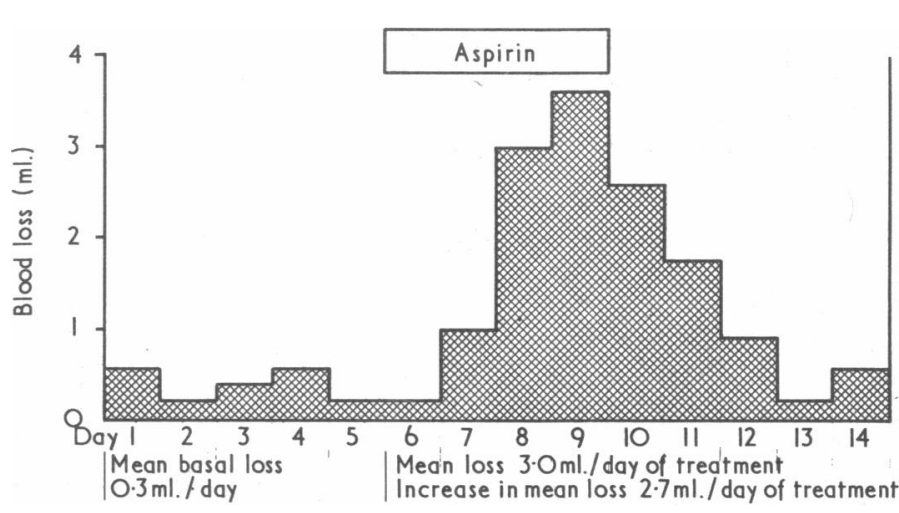

FIG. 2.-Effect of aspirin on gastrointestinal blood loss in patient with pernicious anaemia (Case 11).

\section{Discussion}

The significant increase in aspirin-induced occult gastrointestinal blood loss in patients with pernicious anaemia and proved achlorhydria indicates that hydrochloric acid is not essential for the occurrence of this bleeding. From studies on the canine Heidenhain pouch, Davenport (1965) concluded that bleeding results from back-diffusion of hydrochloric acid into the gastric mucosa after alteration of mucosal permeability by aspirin. While we may not be able to extrapolate our findings on the histologically abnormal mucosa of pernicious anaemia to the normal gastric mucosa, the investigation has shown that aspirin can produce gastrointestinal bleeding by a mechanism unrelated to hydrochloric acid.

Previous studies have reported bleeding in $70-80 \%$ of normal subjects after aspirin ingestion, accepting a total blood loss greater than either 1.5 or $2 \mathrm{ml}$./day of treatment as evidence of bleeding (Pierson et al., 1961; Croft and Wood, 1967). The improved sensitivity of large volume scintillation detectors now available allowed us to assess the response to aspirin by comparison with the basal blood loss. Increased bleeding was found in all 30 patients; had the former methods of calculation been used, some would have been classified as non-bleeders.

The greater blood loss after aspirin in the control group cannot be solely attributed to the presence of hydrochloric acid, for half of the patients had blood losses of similar degree to the pernicious anaemia group, and the degree of blood loss 
in individual members of the control group was unrelated to their gastric acidity. This degree of blood loss has been shown to be remarkably consiant for any individual (Croft and Wood, 1967). It would appear that the control patients with the greater blood loss possess some factor or factors absent in almost all patients with pernicious anaemia as well as in the remaining control patients. Differences in the rate of gastric emptying, gastric mucosal characteristics, or in systemic effects of aspirin may be responsible for the variation in blood loss between individuals.

We are indebted to Mr. K. H. Clarke, physicist-in-charge, Cancer Institute, Melbourne, for allowing us the use of the large volume scintillation detector; to $\mathrm{Mr}$. J. R. Bainbridge, Monash University, for statistical advice; and to the honorary medical staff of Alfred Hospital for permission to study patients admitted under their care.
REFERENCES

Brodie, D. A., and Chase, B. J. (1969). Gastroenterology, 56, 206

Croft, D. N., and Wood, P. H. N. (1967). British Medical fournal, 1, 137.

Davenport, H. W. (1965). Gastroenterology, 49, 189.

Davison, C., Hertig, D. H., and DeVine, R. (1966). Clinical Pharmacology and Therapeutics, 7, 239.

Kay, A. W. (1953). British Medical fournal, 2, 77.

Laws, J. W., and Pitman, R. G. (1960). British fournal of Radiology, 33, 229.

Menguy, R. (1966). Gastroenterology, 51, 430.

Mollison, P. L. (1961). Clinical Science, 21, 21.

Overholt, B. F., and Pollard, H. M. (1968). Gastroenterology, 54, 538.

Pierson, R. N.. jun., Holt, P. R. Watson, R. M., and Keating, R. P. (1961). American fournal of Medicine, ${ }^{2}$.. M.

Roche, M., Perez-Gimenez, M. E., Layrisse, M., and Di Prisco, E. (1957). Fournal of Clinical Investigation, 36, 1183.

Schilling, R. F. (1953). Fournal of Laboratory und Clinical Medicine, 42, 860 .

Winkelman, E. I., and Summerskill, W. H. J. (1961). Gastroenterology, 40, 56.

Wood, I. J., Doig, R. K., Motteram, R., and Hughes, A. (1949). Lancet, 1,18

Wood, P. H. N., Harvey-Smith, E. A., and Dixon, A. St.J. (1962). British Medical fournal, 1, 669

\title{
Effect of Controlled Oxygen Therapy on Arterial Blood Gases in Acute Respiratory Failure
}

\author{
D. A. WARRELL, ${ }^{*}$ B.M., M.R.C.P. ; R. H. T. EDWARDS, ${ }^{*}$ M.B., PH.D., M.R.C.P. ; S. GODFREY, $\ddagger$ M.B., PH.D., M.R.C.P. \\ N. L. JONES, $†$ M.D., M.R.C.P.
}

British Medical fournal, 1970, 2, 452-455

\begin{abstract}
Cummary: Seven patients in acute exacerbation of chronic respiratory failure were given $24.5 \%$ and later $28 \%$ oxygen through Ventimasks. The mean increases in arterial $\mathrm{PO}_{2}$ were 11 and $21 \mathrm{~mm}$. $\mathrm{Hg}$ while breathing $24.5 \%$ and $28 \%$ oxygen respectively compared with control values while breathing air. Associated increases in arterial $\mathrm{PCO}_{2}$ were 4 and $8 \mathrm{~mm}$. $\mathrm{Hg}$, respectively. In five of the patients these increases in inspired oxygen concentration resulted in useful increases in tissue oxygen supply without significant deterioration in ventilation, but in two patients arterial $\mathrm{PCO}_{2}$ rose excessively and artificial ventilation was required.
\end{abstract}

\section{Introduction}

An essential part of the management of respiratory failure occurring in patients with chronic airway obstruction is the relief of hypoxia by increasing inspired oxygen concentration. Campbell (1965) suggested that the continuous administration of $24.5 \%$ or $28 \%$ oxygen might be expected to increase arterial oxygen saturation and tissue oxygen supply by a useful amount with less risk of decreasing ventilation than would be incurred by the use of higher concentrations of oxygen. The present paper reports a study of the effect of $24.5 \%$ and $28 \%$ oxygen administration to patients admitted to hospital with acute respiratory failure. The object was to document the improvement in arterial $\mathrm{PO}_{2}$, study the time course of any changes, and examine the effect on arterial $\mathrm{PCO}_{2}$.

\section{Methods}

Patients.-The seven patients were chronic bronchitics (Medical Research Council, 1965). In five of them, who had been attending an outpatient clinic for cases of respiratory disease, previous values for forced expired volume in the first second (F.E.V.1) had been less than $50 \%$ of predicted normal (Cotes, 1965), indicating chronic severe airway obstruction,

* Medical Registrar, Hammersmith Hospital. London W.12.

†Honorary Lecturer, Royal Postgraduate Medical School, London W.12. Present address: St. Joseph's Hospital, Hamilton, Ontario.

$\ddagger$ Present address: Institute for Diseases of the Chest, Brompton Hospital, London S.W.3. and rebreathing mixed venous $\mathrm{PCO}_{2}\left(\mathrm{P} \overline{\mathrm{v}} \mathrm{CO}_{2}\right)$ (Campbell and Howell, 1960) had been persistently raised, indicating chronic respiratory failure (Table I). They were admitted to hospital during an exacerbation of symptoms associated with evidence of acute worsening of respiratory failure; $\mathrm{P}_{\bar{v}} \mathrm{CO}_{2}$ was above 65 $\mathrm{mm}$. $\mathrm{Hg}$ and at least $15 \mathrm{~mm}$. $\mathrm{Hg}$ higher than the values obtained in the outpatient clinic.

\section{Management}

None of the patients had received oxygen therapy on their way to hospital; they were seen in the emergency department, being accepted into the study on the basis of a clinical assessment and measurement of $\mathrm{P}_{\bar{v}} \mathrm{CO}_{2}$. The patients were moved to the ward and standard treatment with antibiotics, bronchodilators, and diuretics was instituted. Their cooperation in the study was obtained by informed consent. A Teflon cannula was inserted percutaneously into a radial artery and flushed at 15-minute intervals with small amounts of heparinized saline. Blood was sampled for the measurement of arterial gas tensions $\left(\mathrm{PaO}_{2}, \mathrm{PaCO}_{2}\right)$ and lactate concentration, plasma bicarbonate and electrolyte concentrations, blood urea, serum lactic dehydrogenase activity, haemoglobin, packed cell volume, and leucocyte count. After 30 minutes blood gas tensions were again measured. The patients were then started on oxygen through a $24 \%$ Ventimask (Vickers Medical) (Campbell and Gebbie, 1966). Blood gas tensions were measured 15, 30, 60, 120, and 150 minutes later and lactate was measured at 60 minutes. A $28 \%$ Ventimask was substituted at 150 minutes and measurements were repeated $15,30,60$, and 120 minutes later.

The oxygen concentrations produced by Ventimasks were measured in the laboratory with a mass spectrometer (Campbell and Gebbie, 1966). Nominally $24 \%$ masks delivered a mean inspired concentration of 24.3 (S.D. 0.3 ) $\%$ oxygen, and $28 \%$ masks a mean of 28.2 (S.D. 0.4 ) $\%$ oxygen; values of $24.5 \%$ and $28 \%$, respectively, were assumed in the present study. During the study routine observations of clinical state were made and recorded; these included the ability to cough and produce sputum either spontaneously or with help, a measure of the mental state, blood pressure, and heart rate. A portable chest radiograph and an electrocardiogram (E.C.G.) were taken as soon as possible after admission. 